\title{
Prohibición de Discriminación en el Derecho Internacional de los Derechos Humanos
}

Este artículo se encuentra disponible en www.anuariocdh.uchile.cl

Dinah Shelton*

\begin{abstract}
$\mathcal{L a}$ humanidad es tan diversa como el número de personas que la han integrado: cada persona es un individuo único en lo que se refiere a sus atributos y su capacidad, sus metas y habilidades. El Derecho Internacional de los Derechos Humanos reconoce y celebra esta diversidad, intentando garantizar la existencia de las condiciones necesarias para que cada persona pueda ejercer su propia autodeterminación en la realización de sus metas y capacidades lo más plenamente posible, de manera coherente con la realización personal de las demás personas. Para lograr este fin, el derecho no hace hincapié en la diversidad sino en los atributos que comparten los seres humanos y la naturaleza intrínseca de los mismos. En consecuencia, todos/todas tienen los mismos derechos a la libertad de expresión, de aprendizaje, de pensamiento, de derecho a voto, de expresión de opiniones, de desempeño de cargos, de autonomía para contraer matrimonio y tener hijos y de escoger su propia religión. La integridad física y mental de cada persona está garantizada, junto con el acceso equitativo a los servicios públicos, la atención médica, la justicia, la educación y el trabajo. La igualdad y la prohibición de discriminación están implícitas en las garantías formuladas en los instrumentos de derechos humanos que garantizan tales derechos a "todas las personas," a "todo el mundo", o a "todos los seres humanos". En efecto, el derecho de no padecer la discriminación y de gozar de la igualdad en el ejercicio de los derechos se ha denominado "el derecho humano más fundamental: [...] el punto de partida de las demás libertades"1.

Si bien los textos sobre derechos humanos reconocen explícitamente el derecho de "todas las personas", en la práctica es probable que muy pocos o incluso ninguno de los derechos mencionados estén garantizados en plena igualdad de condiciones a todos los seres humanos en todo momento. El derecho a contraer matrimonio y el derecho a voto, por ejemplo, están sometidos a limitaciones determinadas por la edad; el acceso a la justicia está restringido por normas procesales, incluidas las leyes de prescripción, mientras que el costo de presentar una demanda efectivamente puede impedir que algunas personas ejerzan sus derechos; y la garantía de los derechos políticos suele estar limitada a los ciudadanos.
\end{abstract}

Las leyes hacen distinciones. Incluso cuando una ley es aparentemente neutral, puede tener un impacto dispar sobre grupos o individuos específicos, lo que da origen a quejas sobre el carácter discriminatorio de la medida de parte de los afectados. Hay factores estructurales que pueden dejar a ciertos grupos a la zaga en relación con el resto de la sociedad, independientemente de

1 H. Lauterpacht, An InternaTional Bill of the Rights of Man 115 (1945). Sobre la igualdad y la no discriminación en el derecho internacional, ver: A. Bayefsky, The Principle of Equality or Non-Discrimination in International Law, 1 Hum. Rts. L.J. (1990); M. Bossuyt, L'Interdiction de la discrimination dans le droit internatonal des droits de I'homme (1976); Hannikainen \& Nykanen, eds, New Trends in Discrimination law - International Perspectives (1999); W. McKean, The Meaning of Discrimination in International and Municipal Law, 44 BYIL 177 (1970); W. McKean, Equality and Discrimination under International Law (1983); B. G. Ramcharan, Equality and Nondiscrimination, en The International Bill of Rights: The Covenant on Civil and Political Rights, (L. Henkin, ed., 1981), 246-270; E. Vierdag, The Concept of Discrimination in International Law (1973). 
que formalmente reciban un trato equitativo o exista una prohibición de discriminación directa. En consecuencia, es posible que la coherencia en el trato no logre garantizar los objetivos mayores de igualdad, si se aplica por sí sola, sin tomar en cuenta tanto las diferencias como las similitudes existentes en la población.

En principio, la no discriminación como parte de una justicia distributiva implica tratar equitativamente a los que están en situación de igualdad y dar un trato no igualitario a quienes se encuentran en una situación de desigualdad en términos de los criterios pertinentes. La dificultad consiste en determinar cuáles diferencias son pertinentes al comparar la igualdad o la desigualdad de los individuos y los grupos. El problema es doble: es necesario determinar cuáles atributos son pertinentes y decidir cuáles razones son suficientes para hacer distinciones basadas en dichas características. Si bien los instrumentos internacionales de derechos humanos comparten un núcleo central de disposiciones igualitarias, las diferencias de lenguaje entre los distintos textos, la variación en la interpretación de sus disposiciones y la naturaleza de los casos bajo consideración producen una serie de resultados diferentes.

Este artículo intenta evaluar cómo se entiende la prohibición de la discriminación en el Derecho Internacional de los Derechos Humanos contemporáneo. Intenta determinar si existen teorías congruentes que los organismos de derechos humanos aplican de manera coherente al decidir cuáles distinciones están permitidas y cuáles son injustas. El artículo comienza con una evaluación de las disposiciones contenidas en los instrumentos de derechos humanos que exigen la no discriminación y la igualdad ${ }^{2}$. A continuación, el documento analiza la jurisprudencia de los tribunales y organismos de vigilancia internacionales, incluidas las sentencias, opiniones consultivas, observaciones generales, y los comentarios sobre los informes estatales periódicos. En las conclusiones se intenta obtener, a partir de este cuerpo legal, un enfoque general ante la discriminación en el Derecho Internacional de los Derechos Humanos.

Cabe señalar desde un principio que, desde el inicio del siglo XX, la preocupación por la igualdad y la no discriminación se manifestó principalmente en las leyes de responsabilidad estatal relacionadas con los perjuicios ocasionados a los extranjeros ${ }^{3}$ y en la protección otorgada a ciertas minorías nacionales. Después de la Primera Guerra Mundial, se incluyó la protección de los grupos minoritarios entre los requisitos exigidos a los nuevos Estados y a los que fueron derrotados en la guerra. Las cláusulas sobre las minorías garantizaban la no discriminación pero también intentaban preservar la identidad y la cultura de grupos minoritarios cuyas demandas de igualdad y reconocimiento eran consideradas como parte de las causas de pasados conflictos. En consecuencia, los tratados no sólo exigían igualdad de derechos sino que también medidas específicas para la preservación de los grupos protegidos, que carecían del poder político necesario para garantizar dicha preservación por sí mismos ${ }^{4}$. No obstante, estas medidas de protección no eran iguales a la actual acción afirmativa al no tratarse de mecanismos temporales para lograr la igualdad sino, más bien, derechos permanentes para grupos minoritarios en los que las situaciones disímiles entre los grupos mayoritarios y los minoritarios eran tratadas de diferente manera según las necesidades

2 Este documento no analiza en detalle la Convención Internacional sobre la Eliminación de la Discriminación Racial ni el trabajo que realiza el Comité correspondiente. El artículo fue escrito previendo el futuro trabajo de otro autor sobre dicho tema.

3 Por lo general, se considera que la discriminación entre nacionales y extranjeros es una violación del derecho internacional, que habitualmente surge en casos de expropiación de bienes. Ver por ejemplo J.H. Herz, Expropriation of Foreign Property, 35 AJIL 243 (1941); S. Friedman, Expropriation in International Law 189-93 (1953); Gillian White, The Nationalization OF FOREIGN PROPERTY (1961), cap. 6. En términos más generales, ver Shigeru Oda, The Individual in International Law, en M. Sorensen, ed. Manual of Public International Law 486 (1968).

4 Para una discusión sobre la historia de la redacción del Convenio de la Liga de las Naciones y los esfuerzos infructuosos por incluir disposiciones sobre la igualdad racial y religiosa, ver MCKeAN supra n. 2, 14-26. 
propias de sus distintas situaciones. De este modo, se garantizaron los derechos lingüísticos de los grupos, la separación de las instituciones educativas y religiosas, una participación equitativa en los fondos públicos y el respeto de los feriados religiosos ${ }^{5}$. La igualdad conforme a la ley prohibía la discriminación de todo tipo, mientras que la igualdad de hecho debió ser tratada de otra forma con el fin de lograr el "equilibrio" entre quienes se encontraban en situaciones distintas ${ }^{6}$.

\section{La igualdad y la no discriminación en la Carta de las Naciones Unidas y los organismos crea- dos a partir de la misma}

Un delegado al Tercer Comité de la Asamblea General de las Naciones Unidas afirmó en una ocasión que "la Organización de las Naciones Unidas se fundó principalmente para luchar contra la discriminación en el mundo" 7 . Los comentaristas concuerdan en que la igualdad y la no discriminación "son fundamentales para el movimiento por los derechos humanos" ${ }^{8}$. En efecto, los objetivos manifiestos de las Naciones Unidas, que dieron origen al escenario para el trabajo de la ONU en el ámbito de los derechos humanos, demuestran la inquietud de los redactores por la igualdad y la no discriminación:

Los propósitos de las Naciones Unidas son:

1. Mantener la paz y la seguridad internacionales [...];

2. Fomentar entre las naciones relaciones de amistad basadas en el respeto a los principios de igualdad de derechos y de libre determinación de los pueblos [...];

3. Realizar la cooperación internacional en[...] el desarrollo y estímulo del respeto a los derechos humanos y a las libertades fundamentales de todos, sin hacer distinción por motivos de raza, sexo, idioma o religión.

(Carta de las Naciones Unidas, artículo 1. Énfasis añadido)

Entre las múltiples referencias incluidas en la Carta de la ONU a los derechos humanos, sólo se mencionan explícitamente dos derechos: la libre determinación y la no discriminación. Salvo por una excepción en el artículo 62, cada vez que en la Carta de la ONU aparece la frase "derechos humanos y libertades fundamentales" es seguida de las palabras "sin discriminación por motivos de raza, sexo, idioma o religión". Si bien se han ampliado considerablemente las razones que prohíben la discriminación en los textos y la jurisprudencia posteriores, la combinación de un enfoque centrado en la igualdad y la libre determinación ha orientado gran parte del trabajo de los organismos de las Naciones Unidas en el campo de los derechos humanos.

5 En su primera Opinión Consultiva, el Tribunal Permanente declaró que, en virtud de los tratados sobre las minorías, debía existir tanto "la igualdad de hecho como una igualdad ostensible en el sentido de la ausencia de discriminación en el lenguaje de la ley". Settlers of German Origin in Poland, 6 PCIJ (Ser. B) (1923), p. 24.

6 Minority Schools in Albania, PCIJ [1923], ser. A/B, No 64, 19 se basa en una ley aparentemente neutral (eliminación de todas las escuelas privadas), cuyo impacto era dispar y discriminatorio (en opinión del tribunal) respecto de la población minoritaria griega en Albania. Ver también la Opinión Consultiva sobre Treatment of Polish Nationals and Persons of Polish Origin or Speech in the Territory of the Free City of Danzig, PCIJ [1932], Ser. A/B, No 44.

7 UN Doc. A/C.3/SR 100, p. 7, citado en McKean, supra n. 2, 177.

8 Jerome Shestack, The Jurisprudence of Human Rights en Human Rights in International Law: LeGal and Policy Issues (Th. Meron, ed., 1984), p. 101. John Humphrey afirma que la discriminación, al igual que los derechos humanos, está presente en toda la Carta de las Naciones Unidas como "un hilo dorado". John P. Humphrey, Preventing Discrimination and Positive Protection for Minorities: Aspects of International Law en 27 Les CAHIER DE Droit 23, 27 (1986). 
La ONU recalcó su compromiso con la lucha contra la discriminación en los mandatos que los Estados Miembros otorgaron a sus nuevos organismos. La antigua Comisión de Derechos Humanos estaba encargada de la protección de las minorías y la prevención de la discriminación por motivos de raza, sexo, idioma o religión ${ }^{9}$. El Consejo Económico y Social (ECOSOC por sus siglas en inglés) facultó a la Comisión para que creara una subcomisión sobre este tema, a saber, la Subcomisión de Prevención de Discriminaciones y Protección a las Minorías ${ }^{10}$. El Consejo Económico y Social creó, asimismo, la Comisión de la Condición Jurídica y Social de la Mujer para promover la igualdad entre hombres y mujeres, sin distinción por motivos de nacionalidad, raza, idioma ni religión, con el fin adicional de eliminar todas las formas de discriminación contra la mujer en el derecho y en la práctica.

Desde un principio, los Estados Miembros de la ONU invocaron las referencias que la Carta de dicho organismo hace a la igualdad de derechos para manifestarse en contra de la discriminación. Durante el primer período de sesiones de la Asamblea General en 1946, India criticó la segregación en Estados Unidos, ante lo cual EE.UU. respondió con un ataque contra el sistema de castas de la India ${ }^{11}$. Egipto, con el respaldo de los Estados latinoamericanos, presentó una resolución, que fue aprobada en forma unánime, condenando la persecución racial y religiosa ${ }^{12}$. Una resolución auspiciada por la India condenando a Sudáfrica por sus políticas sistemáticas de discriminación racial fue aprobada por la mayoría exigida de dos tercios, a pesar de las objeciones de Australia, Gran Bretaña, Canadá y Estados Unidos, países que tenían sus propias políticas raciales contrarias a las garantías reconocidas en la Carta de la ONU ${ }^{13}$. La primera reunión de la Asamblea General incluyó también el tema del genocidio, que fue declarado un delito en virtud del Derecho Internacional ${ }^{14}$.

En los siguientes períodos de sesiones de la Asamblea General se produjeron condenas similares en contra de la discriminación. En efecto, durante los primeros 30 años de los debates sobre los derechos humanos en la Asamblea General y el ECOSOC ${ }^{15}$, la discriminación racial fue la cuestión que apareció con mayor frecuencia en la agenda, ocupando casi la misma cantidad de tiempo

9 Informe del Comité Ejecutivo a la Comisión Preparatoria de las Naciones Unidas, UN doc PC/EX/113/rev. 1 (12 de Nov. de 1945), 52-3.

10 Durante sus primeros años, la Subcomisión asumió el compromiso de estudiar la discriminación en la educación, ocupación y el empleo, derechos políticos y religiosos, residencia, y libertad de movimiento. Ver: Study of Discrimination in Education, de C.D. Ammoun, E/CN.4/Sub.2/181/rev. 1 (1956); Study of Discrimination in Respect of Religious Rights, de A. Krishnaswami, E/CN.4/Sub.2/200/rev. 1 (1959); Study of Discrimination in Respect of Political Rights, de H. Santa Cruz, E/CN.4/Sub.2/213/rev. 1 (1961) y E/CN.4/Sub.2/370 (1976); Study of discrimination in Respect of the Right of Everyone to Leave any Country, including his own, and to Return to his own County, de J.D. Ingles, E/Cn.4/Sub.2/220 (1960); The Study of Discrimination against Persons born out of Wedlock, de V.V. Saario, E/Cn.4/Sub.2/265 (1966); Study of Racial Discrimination in the Political, Economic, Social and Cultural Spheres, de H. Santa Cruz, E/CN.4/Sub.2/288 (1968); Study of Discrimination against Indigenous Peoples, de J.M. Cobo, E/CN.4/Sub.2/415. En 1952, la OIT comenzó a estudiar la discriminación en el trabajo y la ocupación, que redundó en una convención sobre el tema. Además, el estudio de la Subcomisión sobre la discriminación en la educación, realizado con la colaboración de UNESCO, permitió completar la Convención de UNESCO sobre discriminación en la enseñanza.

11 Id., 207.

12 Res. 103(1), 48 período de sesiones. (29 Nov. 1946), UN doc. A/64/add.1, 200. La resolución hace un Ilamamiento para poner fin a la persecución racial y religiosa y la discriminación, además de pedir que los estados cumplan con la letra y el espíritu de la Carta de la ONU.

13 Resolución 44(I), I (pt. 2) GAOR, Resolutions, U.N. Doc. A/64/Add.1, 69 (1946). El tema de las políticas raciales de Sudáfrica se mantuvo en la agenda de las Naciones Unidas en cada reunión hasta el fin del apartheid.

14 Res. 96(1), sobre el delito de genocidio.

15 Jack Donnelly, Human Rights at the United Nations, 1955-1985: The Question of Bias, 32 INT'L STUD. Q. 275 (1988). Donnelly atribuye el hecho de que la ONU se centrara en la discriminación racial y la autodeterminación al número creciente de miembros de países africanos y asiáticos en lugar de al lenguaje utilizado en la Carta de la ONU. Id., 277. 
que el conjunto de temas de todos los derechos civiles y políticos. En 1962, la Asamblea General creó el Comité Especial sobre las Políticas de Apartheid del Gobierno de Sudáfrica. Varios años después, mediante la Resolución 2145 (XXI) del 27 de octubre de 1966, la Asamblea General puso fin al mandato de Sudáfrica respecto de África Sudoccidental (actualmente Namibia). En una Opinión Consultiva emitida en 1971, la Corte Internacional de Justicia determinó que la denegación de derechos humanos y libertades fundamentales de parte de Sudáfrica por motivos de raza era "una violación flagrante de los propósitos y principios de la Carta de la ONU". De esta manera, la Corte recalcó la importancia de la no discriminación en el lenguaje de la Carta y en la práctica de los organismos de la ONU.

\section{Tratados universales y regionales sobre derechos humanos}

La Declaración Universal de los Derechos Humanos (DUDH) [A.G. Res. 217A (III), ONU Doc. A/810 p. 71 (1948)], inicia su Preámbulo con una reafirmación de la solidaridad humana, el reconocimiento de la dignidad intrínseca y de "los derechos iguales e inalienables de todos los miembros de la familia humana". El artículo 1 declara que "[t]odos los seres humanos nacen libres e iguales en dignidad y derechos" mientras que el artículo 2 agrega que toda persona tiene los derechos y libertades proclamados en la DUDH "sin distinción alguna de raza, color, sexo, idioma, religión, opinión política o de cualquier otra índole, origen nacional o social, posición económica, nacimiento o cualquier otra condición". La utilización de las palabras "sin distinción alguna"16 y la inclusión del término "o cualquier otra condición" deja en claro que la lista no es una enumeración exhaustiva. El artículo 7 establece la igualdad ante la ley y el derecho a igual protección de la ley como asimismo el derecho a la igual protección contra toda discriminación y contra la provocación a tal discriminación. Dicha disposición está reforzada por el artículo 10 que señala que toda persona tiene derecho "en condiciones de plena igualdad" a ser oída públicamente y con justicia por un tribunal independiente e imparcial. El derecho a contraer matrimonio, al que se refiere el artículo 16, queda garantizado "sin restricción alguna por motivos de raza, nacionalidad o religión". Se otorga derechos iguales a hombres y mujeres en cuanto al matrimonio, durante el matrimonio y en caso de la disolución del mismo. En tanto, el artículo 23 garantiza a todos el derecho a igual salario por trabajo igual.

Como indican las disposiciones de la DUDH, términos tales como "igualdad", "igual protección", "no discriminación" y "sin distinción" aparentemente se utilizan indistintamente. Este uso también se presenta en tratados redactados poco después, en la Convención Internacional sobre la Eliminación de todas las Formas de Discriminación Racial de 1965 (CIEDR) [Serie Tratados de Naciones Unidas, Vol. 660, p. 195], y en los dos Pactos ${ }^{17}$ cuyos artículos en los que se prohíbe la discriminación reconocen también que las disposiciones sobre igualdad no se pueden interpretar como una exigencia de igual trato en términos absolutos porque puede que sea pertinente o incluso necesario realizar algunas distinciones relativas a las clasificaciones legales ${ }^{18}$. Por ejemplo, algunas

\footnotetext{
16 Nota de la editora: en inglés la Declaración utiliza la expresión "such us", cuya traducción literal sería "tales como", pero la versión oficial en español que la Declaración utiliza fue traducida como "sin distinción".

17 Pacto Internacional de Derechos Económicos, Sociales y Culturales, 19 Dic. 1966, 999 UNTS (en adelante PIDESC); Pacto Internacional sobre Derechos Civiles y Políticos, 19 Dic. 1966, GA Res. 2200A (XXI), 999 UNTS 171 (en adelante PIDCP).

18 Por mucho tiempo, se ha afirmado que otorgar igual trato a quienes no son iguales debiera ser considerado un error similar a tratar en forma desigual a quienes son iguales. Este principio subyace la aceptación de la acción afirmativa en favor de miembros de grupos menos privilegiados. Ver UN Doc. A/C.3/SR.1182 párrafo 17 (1962). Y A/C.3/SR.1259. Los miembros del PIDCP han señalado que las medidas positivas a favor de un grupo menos privilegiado pueden ser "esenciales" en determinados casos. UN Doc. PIDCP/C/SR.189, párrafos 10, 14 (1980).
} 
disposiciones plantean distinciones explícitas que prohíben la aplicación de la pena de muerte a quienes tenían menos de 18 años al momento de cometer el delito, como también a las mujeres embarazadas (artículo 6 (5) del Pacto Internacional sobre Derechos Civiles y Políticos-PIDCP); el requisito de mantener separados a los infractores juveniles y adultos y a las personas acusadas de un delito respecto de aquellas que ya han sido condenadas (PIDCP, artículo 10); y la limitación de algunos derechos políticos a los ciudadanos de un país (PIDCP, artículo 25).

Entre los primeros tratados sobre derechos humanos, solamente el CIEDR, el Convenio 111 de la Organización Internacional del Trabajo (OIT) relativo a la discriminación en materia de empleo y ocupación, y la Convención relativa a la lucha contra las discriminaciones en la esfera de la enseñanza (Organización de las Naciones Unidas para la Educación, la Ciencia y la Cultura, UNESCO por sus siglas en inglés, 1960) definían el término discriminación. Posteriormente, la Convención sobre la eliminación de todas las formas de discriminación contra la mujer (CEDAW, por sus siglas en inglés) ${ }^{19}$ y la Convención internacional sobre la protección de los derechos de todos los trabajadores migratorios y de sus familiares ${ }^{20}$ agregaron sus propias disposiciones. En general, los respectivos artículos establecen que, para los fines de cada convenio, el término discriminación significa cualquier distinción, exclusión o restricción (CIEDR agrega "o preferencia") cuyo efecto o propósito perjudica o anula el reconocimiento, disfrute o ejercicio de los derechos humanos en forma igualitaria (CIEDR agrega "y las libertades fundamentales") en la esfera política, económica, social y cultural (CEDAW agrega la civil) o cualquier otro ámbito (CIEDR agrega "de la vida pública"). A diferencia del artículo 2(1) de PIDCP y el artículo 14 del Convenio Europeo para la Protección de los Derechos Humanos y las Libertades Fundamentales (ECHR, por sus siglas en inglés), que sólo se refieren a distinciones en el goce de los derechos reconocidos por los respectivos tratados, CIEDR y CEDAW prohíben la discriminación en lo que se refiere a todos los derechos y las libertades garantizadas por el derecho nacional e internacional. Las medidas temporales de trato preferencial dirigido a las mujeres o a ciertos individuos o grupos raciales y étnicos desfavorecidos no se consideran discriminatorias si su único propósito es garantizar el progreso hacia la igualdad [Ver CIEDR, artículo 1(4) y CEDAW artículo 4(2)]. En textos recientes, se ha reconocido que las personas pueden formar parte de más de un grupo desfavorecido, lo cual incrementa su situación de discriminación. Por ejemplo, en la Declaración de Durban y Programa de Acción se reconoció que la discriminación racial puede verse agravada por múltiples formas de discriminación basadas en otros motivos, tales como el sexo, idioma, religión, opiniones políticas o de otra índole, origen social, posición económica o de nacimiento o cualquier otra condición ${ }^{21}$.

El Convenio 111 de la OIT relativo a la discriminación en materia de empleo y ocupación de 1958 fue, quizás, el primer instrumento internacional en el que se definió la discriminación. Durante la redacción del documento, la discriminación se definió provisionalmente como cualquier distinción negativa por la cual se priva a alguien de la igualdad de oportunidad o trato en su trabajo y su

19 Convención sobre la eliminación de todas las formas de discriminación contra la mujer, 18 Dic. 1979, GA res. 34/180, UN GAOR Supp. № 46, 193, UN Doc. A/34/46.

20 La Convención internacional sobre la protección de los derechos de todos los trabajadores migratorios y de sus familiares fue aprobada por la Asamblea General mediante resolución 45/158 del 18 de diciembre de 1990 y, en su artículo 7, establece una disposición en contra de la discriminación: "Los Estados Partes se comprometerán, de conformidad con los instrumentos internacionales sobre derechos humanos, a respetar y asegurar a todos los trabajadores migratorios y sus familiares que se hallen dentro de su territorio o sometidos a su jurisdicción los derechos previstos en la presente Convención, sin distinción alguna por motivos de sexo, raza, color, idioma, religión o convicción, opinión política o de otra índole, origen nacional, étnico o social, nacionalidad, edad, situación económica, patrimonio, estado civil, nacimiento o cualquier otra condición".

21 Declaración de Durban y Programa de Acción aprobados por la Conferencia Mundial contra el Racismo, la Discriminación Racial, la Xenofobia y la Intolerancia relacionada (2001), párrafo 2. 
ocupación, que se base en cuestiones de raza, color, sexo, religión, opiniones políticas, origen nacional o social ${ }^{22}$. El Comité de Expertos en Discriminación propuso agregar una disposición que permitiera dejar en claro que esta definición no debía aplicarse a las diferencias establecidas a partir de una consideración objetiva de las necesidades auténticas o los requisitos inherentes a los diferentes tipos de trabajo ${ }^{23}$. Otra propuesta, que se plasmó en el artículo 5, excluía de la definición las medidas especiales de protección o asistencia que permiten otras Convenciones o recomendaciones de la OIT y, lo que es más problemático, permitían que cualquier miembro considerara como no discriminatorias otras medidas especiales de protección conforme a los requisitos particulares de las personas por razones de sexo, edad, discapacidad, responsabilidades familiares o su condición social o cultural ${ }^{24}$. Finalmente, el artículo 1 definió la discriminación como cualquier distinción, exclusión o preferencia que se base en cuestiones de raza, color, sexo, religión, opinión política, ascendencia nacional u origen social cuyo efecto sea anular o alterar la igualdad de oportunidades o de trato en el empleo y la ocupación, con la salvedad de que se pueden aplicar requisitos ocupacionales de buena fe. Asimismo, los Estados Miembros quedaron facultados para agregar categorías adicionales de distinciones prohibidas, pero el idioma, la edad y la ciudadanía quedaron omitidos mientras que se consideró que las opiniones políticas excluían las medidas adoptadas en contra de una persona sobre la cual recaiga una sospecha legítima de estar involucrado en una actividad perjudicial para la seguridad del Estado o acerca de la cual se haya establecido que efectivamente se dedica a esta actividad $^{25}$-abriendo de esta manera la posibilidad a abusos considerables ${ }^{26}$.

La UNESCO fue creada en parte para paulatinamente convertir en realidad "el ideal de la igualdad de posibilidades de educación para todos sin distinción de raza, sexo ni condición social o económica alguna" [Constitución de UNESCO, artículo I. 2(b)]. El 14 de diciembre de 1960, UNESCO aprobó su propia Convención relativa a la lucha contra las discriminaciones en la esfera de la enseñanza, la cual entró en vigencia el 22 de mayo de 1962. El artículo 1 de la Convención define como discriminación "toda distinción, exclusión, limitación o preferencia fundada en la raza, el color, el sexo, el idioma, la religión, las opiniones políticas o de cualquier otra índole, el origen nacional o social, la posición económica o el nacimiento, que tenga por finalidad o por efecto destruir o alterar la igualdad de trato en la esfera de la enseñanza". La Convención da ejemplos de prácticas reprobables específicas tales como: (a) privar a una persona o a un grupo del acceso a los diversos grados y tipos de enseñanza; (b) limitar la educación de una persona o de un grupo a una calidad inferior; (c) instituir o mantener sistemas o establecimientos de enseñanza separados para determinadas personas o grupos (excepto para estudiantes de sexo femenino y minorías lingüísticas y religiosas que así lo deseen ); y (d) colocar a una persona o

22 Acta de Sesiones, I.L. Conf., 40 período de sesiones, 1957, 741.

23 I.L. Conf., 42 período de sesiones, 1958, informe IV91), 29.

24 Acta de Sesiones, I.L. Conf., 42 período de sesiones. 1958, 713.

25 artículo 4.

26 La jurisprudencia del Comité de Derechos Humanos ha permitido otorgar trato preferencial a quienes anteriormente fueron rechazados erróneamente por motivos políticos. Ver, por ejemplo, Stalla Costa v. Uruguay, No 198/1985, en que el peticionario se quejó de trato preferencial en el ingreso al servicio público otorgado a ex funcionarios públicos despedidos por razones ideológicas, políticas o sindicales por el anterior régimen militar. El peticionario se quejó de que dicho trato preferencial perjudicaba injustamente sus propias posibilidades de obtener un cargo en el servicio público. El Comité señaló que quienes habían sido objeto de la preferencia eran víctimas de la violación al derecho a igual participación ciudadana en la vida pública en virtud del artículo 25 de IPIDCP y que, en tal condición, tenían derecho a una reparación efectiva en virtud del artículo 2, párrafo 3 (a) de IPIDCP. La promulgación de la ley objetada constituía dicha reparación. Por lo tanto, no había una violación del artículo 25 (c) ni discriminación conforme al significado establecido en los artículos 2 y 26 del Pacto. Se determinó que la supuesta discriminación era una "medida de reparación" admisible dirigida a personas que previamente habían sido objeto de discriminación. 
a un grupo de personas en una situación incompatible con la dignidad humana. Si el Estado las admite, el artículo 2(1) permite la creación o mantenimiento de sistemas o establecimientos de enseñanza separados para alumnos de sexo masculino o femenino, pero esto resulta problemático ya que sólo requiere que ofrezcan facilidades equivalentes de acceso a la enseñanza que permitan seguir los mismos programas de estudio o programas equivalentes. Posteriormente, el artículo 10 de CEDAW reforzó las garantías educacionales para niñas y mujeres al exigir que los Estados Partes proporcionen "las mismas" oportunidades en la esfera de la educación en lugar de sólo otorgar oportunidades "equivalentes". Los Estados Partes están obligados a adoptar todas las medidas apropiadas para eliminar las leyes y prácticas discriminatorias en la educación. Se les exige, asimismo, que adopten medidas positivas para garantizar la no discriminación en la esfera de la enseñanza que proporciona el sector privado $^{27}$.

EI PIDCP replantea muchas de las disposiciones de la DUDH pero impone, además, obligaciones a cada Estado Parte en cuanto a comprometerse a respetar y a garantizar los derechos reconocidos en el Pacto a todas las personas que se encuentren en su territorio y que estén sujetas a su jurisdicción "sin distinción alguna de raza, color, sexo, idioma, religión, opinión política o de otra índole, origen nacional o social, posición económica, nacimiento o cualquier otra condición social". La Asamblea General agregó el artículo 3, que establece la igualdad entre hombres y mujeres en el goce de derechos con el fin de recalcar y hacer hincapié en la obligación de no discriminación. El artículo 26 exige la protección efectiva contra la discriminación en lo que se refiere a todos los derechos y beneficios reconocidos por ley mientras que el artículo 20 impone la obligación de prohibir cualquier apología del odio nacional, racial o religioso que constituya una incitación a la discriminación, la hostilidad o la violencia. Consideradas en conjunto, estas disposiciones transforman a la no discriminación en el "tema único y predominante" del Pacto.

Al igual que el PIDCP, el Pacto Internacional de Derechos Económicos, Sociales y Culturales (PIDESC) prohíbe la discriminación de cualquier tipo en cuanto al goce de los derechos que abarca el Pacto, salvo por una excepción notable y polémica. El artículo 2(3) establece que "Ios países en desarrollo, teniendo debidamente en cuenta los derechos humanos y su economía nacional, podrán determinar en qué medida garantizarán los derechos económicos reconocidos en el presente Pacto a personas que no sean nacionales suyos". Muchos países occidentales arguyeron que esta disposición destruía un principio básico de los Pactos, a saber, el de la no discriminación ${ }^{28}$. Los defensores de la disposición afirmaron que era necesaria para eliminar la desigualdad económica entre los nacionales de los países en desarrollo y los países desarrollados.

El tratado internacional más reciente sobre derechos humanos de la ONU, la Convención sobre los Derechos de las Personas con Discapacidad ${ }^{29}$, trata fundamentalmente sobre la igualdad y la no discriminación, y reconoce la necesidad de promover y proteger los derechos humanos de todas las personas discapacitadas, incluso aquellas que requieren de un apoyo mayor. La Convención declara que la "discriminación contra cualquier persona por razón de su discapacidad constituye una vulneración de la dignidad y el valor inherentes del ser humano". El artículo 5 establece las obligaciones fundamentales de las partes, haciendo hincapié en la igualdad de derechos de

27 Durante los estudios preliminares y la redacción de la Convención, los Estados discutieron el tema de las medidas de protección y la compensación destinadas a ayudar a quienes anteriormente habían sido discriminados, en la que predominó el criterio de que el sistema de cuotas no correspondía porque no consideraría el mérito individual. Ver UN Doc. E/CN.4/721, s. 5 y UN doc. E/CN.4/740.

28 UN doc. A/C3/SR 1207, 362. Este párrafo fue aprobado con un estrecho margen de 41 votos contra 38 y 12 abstenciones. UN docs. A/5365, 22-23; A/C3/L.1027/revs. 1-4; A/5365, 15-16.

29 Aprobada por la Asamblea General de la ONU, 13 de Dic. de 2006. La Convención entrará en vigencia 30 días después de su vigésima ratificación o adhesión. Al 10 de Dic. de 2007, 12 Estados la habían ratificado. 
todas las personas, junto con exigir que se realicen ajustes razonables frente a las diferencias pertinentes.

1. Los Estados Partes reconocen que todas las personas son iguales ante la ley y en virtud de ella, y que tienen derecho a igual protección legal y a beneficiarse de la ley en igual medida sin discriminación alguna.

2. Los Estados Partes prohibirán toda discriminación por motivos de discapacidad y garantizarán a todas las personas con discapacidad protección legal igual y efectiva contra la discriminación por cualquier motivo.

3. A fin de promover la igualdad y eliminar la discriminación, los Estados Partes adoptarán todas las medidas pertinentes para asegurar la realización de ajustes razonables.

4. No se considerarán discriminatorias, en virtud de la presente Convención, las medidas específicas que sean necesarias para acelerar o lograr la igualdad de hecho de las personas con discapacidad.

El artículo 12 agrega la igualdad de reconocimiento ante la ley mientras que el resto de la Convención refleja el doble objetivo de igual trato siempre que sea posible junto con el respeto por las diferentes necesidades y la diversidad de los discapacitados.

En el ámbito regional, el artículo 14 del Convenio Europeo para la Protección de los Derechos Humanos y las Libertades Fundamentales [4 de noviembre de 1950, ETS 5], prohíbe la discriminación en cuanto al goce de los derechos reconocidos por el Convenio. Se ha considerado que el artículo 14 es una disposición "prácticamente parasitaria, que carece de existencia independiente ya que está vinculada exclusivamente al goce de los derechos y las libertades establecidas en otras disposiciones sustantivas" ${ }^{30}$. El Tribunal Europeo ha llegado a la conclusión de que la discriminación ilícita se produce cuando hay un (i) trato diferente de personas que se encuentran en situaciones análogas o fundamentalmente similares y que (ii) la diferencia de trato carece de "justificación objetiva y razonable". Se establece la existencia de la "justificación objetiva y razonable" si la medida en cuestión tiene un propósito legítimo y existe una "proporcionalidad razonable entre los medios empleados y los objetivos que se intenta lograr" ${ }^{\prime 31}$. Anteriormente, el Tribunal Europeo se había negado a menudo a considerar un reclamo de discriminación luego de descubrir una violación de uno de los derechos consagrados en el Convenio pero, al parecer, este enfoque cambió hace unos años ${ }^{32}$.

\footnotetext{
30 Luzius Wildhaber, Protection against Discrimination under the European Convention on Human Rights - A Second-Class Guarantee? 2 BALTIC Y.B. INT'L L. 71, 72 (2002).

31 Ver Belgian Linguistics case, $\mathrm{N}^{\circ}$ s. 1474/62, etc., 23/07/1968, párrafo 10.

32 En Dudgeon v. United Kingdom, 45 Eur.Ct.H.R. (serie A)(1981), 4 EHRR 149 (1982), por ejemplo, el Tribunal señaló que "no se contribuirá a fin legal alguno" al analizar una demanda de discriminación una vez que se ha detectado la violación de otro derecho fundamental. Id., párrafo 69. Este enfoque constituye una subvaloración considerable del daño adicional que implica la negación de un derecho por motivos de discriminación. En Nachova and Others v. Bulgaria, Apps $N^{\circ} 43577 / 98$ y 43579/98, en la sentencia dictada el 6 de julio de 2005 (GC) el Tribunal adoptó una postura diferente. La Gran Cámara sostuvo que las autoridades no cumplieron con su deber en virtud del artículo 14 de la Convención entendido en conjunto con el artículo 2 de tomar todas las medidas posibles para establecer si es que actitudes discriminatorias pudieron haber influido en la muerte, a manos de la policía, de dos jóvenes de origen Roma. Según el Tribunal, las autoridades estatales tienen el deber de tomar todas las medidas razonables para descubrir cualquier motivación racista y para establecer si es que el odio o prejuicio étnico pudieron haber influido en los hechos [la muerte ocasionada por agentes del Estado]. "No hacer esto y tratar la violencia y brutalidad racial de igual manera que casos sin motivación racista sería cegarse ante la naturaleza específica de hechos que son particularmente destructivos de los derechos fundamentales". Más adelante, el Tribunal agrega que el hecho de no tomar en cuenta esa motivación puede, en sí, constituir una violación del artículo 14. Nachova, párrafo 158.
} 
A raíz de las inquietudes ocasionadas por las limitaciones del artículo 14 del Convenio, el Consejo de Europa elaboró el Protocolo № 12, que entró en vigencia el 1 de abril de 2005 . El Protocolo prohíbe la discriminación respecto del goce de cualquier derecho establecido por ley, en reconocimiento de la necesidad de la existencia de un derecho "independiente" o "autónomo" con el fin de fortalecer la protección de la igualdad otorgada por el Convenio. Sin embargo, el preámbulo del Protocolo 12 reitera que el principio de no discriminación no impide que los Estados implementen medidas de acción afirmativa, a condición de que se justifiquen objetiva y razonablemente.

Dentro de la Unión Europea, el artículo 13 del Tratado de la Comunidad Europea otorga a la Unión Europea poderes específicos para luchar contra la discriminación por motivos de sexo, origen racial o étnico, religión o convicciones, edad, discapacidad u orientación sexual. En virtud de este mandato, el Consejo aprobó dos Directivas ${ }^{33}$ que prohíben la discriminación directa e indirecta, lo cual incluye el acoso por motivos raciales, religiosos o relacionados con las convicciones, la discapacidad, edad, y la orientación sexual en el trabajo y el empleo, incluida la enseñanza y la educación vocacional, la pertenencia a organismos profesionales o similares; la protección social; el acceso a bienes y servicios disponibles para el público y la oferta de los mismos; y las "ventajas sociales" (por ejemplo, precios reducidos en el transporte público y en el acceso a eventos culturales o de otra índole, además de la alimentación subsidiada que se otorga en las escuelas a niños provenientes de familias de escasos recursos).

El artículo 1(1) de la Convención Americana sobre Derechos Humanos [22 de noviembre de 1969, que entró en vigor el 18 de julio de 1978] y el artículo 2 de la Carta Africana sobre los Derechos Humanos y de los Pueblos [Banjul, 26 de junio de 1981, vigente desde el 21 de octubre de 1986] consagran el derecho de todas las personas a gozar de todos los derechos garantizados sin discriminación. Las disposiciones de la Convención Americana prohíben la discriminación en términos generales incluyendo entre los motivos "cualquier otra condición social" con lo que indica que se trata de una prohibición general en contra de la discriminación, como es el caso de algunos tratados de la ONU que prohíben la discriminación sobre la base de "cualquier otra condición". El artículo 24 agrega una garantía de igualdad ante la ley e igual protección de la ley, de manera análoga al artículo 26 de PIDCP. En la Opinión Consultiva OC-4/84, la Corte Interamericana de Derechos Humanos señala que el artículo 1(1) depende de su vinculación con un derecho garantizado por la Convención mientras que el artículo 24 garantiza la igualdad no sólo en lo referente al goce de los derechos establecidos en la Convención sino también en la aplicación de cualquier norma interna.

La Carta Africana sobre los Derechos Humanos y de los Pueblos, además de la prohibición general contra la discriminación establecida en el artículo 2, agrega que todos los individuos serán iguales ante la ley y tendrán derecho a igual protección de la ley (artículo 3), con lo que agrega una garantía "autónoma" de no discriminación similar a la del artículo 26 del PIDCP y el artículo 24 de la Convención Americana de Derechos Humanos. El artículo 12(5) reconoce el considerable problema que implica la expulsión masiva y discriminatoria de extranjeros. El artículo 18(3) establece, además, que cada Estado Parte deberá hacerse responsable de eliminar la discriminación en contra de las mujeres como también de la protección de sus derechos. Por último, a diferencia de otros instrumentos internacionales y regionales que se centran exclusivamente en el individuo, la Carta Africana explícitamente prohíbe la dominación o la discriminación

33 Directiva del Consejo 2000/43/EC del 29 de junio del 2000 que pone en práctica el principio de trato igual entre las personas sin consideración de su origen racial o étnico (la "Directiva Racial") y la Directiva del Consejo 2000/78/EC, que establece el marco general para el trato igualitario en el trabajo y la ocupación (la "Directiva del Marco General"). 
de parte de un grupo de personas respecto de otro, incluyendo en ello al desarrollo económico, social y cultural. El 11 de julio del 2003, la Unión Africana complementó la Carta de la ONU con un Protocolo aparte y detallado sobre los Derechos de la Mujer en África, que entró en vigor el 25 de noviembre de 1995 y que está centrado en el principio de la igualdad en cuanto al sexo y el género. El Protocolo prohíbe la discriminación directa e indirecta "en todos los ámbitos de la vida" y promueve la acción positiva.

Todos los tratados sobre derechos humanos que permiten que los Estados suspendan derechos mediante su derogación en caso de emergencia nacional incluyen un requisito de no discriminación en las disposiciones pertinentes. El PIDCP, por ejemplo, establece que cualquier medida impuesta por un Estado luego de proclamar oficialmente la existencia de una situación excepcional basándose en la notificación de su derogación "no entrañe discriminación alguna fundada únicamente en motivos de raza, color, sexo, idioma, religión u origen social" [artículo 4]. El lenguaje del artículo 27 de la Convención Americana es casi idéntico.

La omnipresencia de las obligaciones contraídas en los tratados en cuanto a la no discriminación, la igualdad de derechos, la igualdad ante la ley en conjunto con las leyes y prácticas nacionales, proporcionan evidencia adecuada de que una norma de no discriminación, en cuanto al respeto y observancia de los derechos humanos y las libertades fundamentales, actualmente se considera parte del corpus de la costumbre internacional ${ }^{34}$. En efecto, la Corte Interamericana de Derechos Humanos ha denominado la prohibición de la discriminación como parte del jus cogens ${ }^{35}$. Empleando otro enfoque, la ex Comisión Europea de Derechos Humanos sostuvo que algunas formas de discriminación pueden ser constitutivas de tratos degradantes ${ }^{36}$.

\section{Significado y alcance de la prohibición de discriminación}

Algunos de los primeros Relatores Especiales de la ONU nombrados por la Subcomisión se esforzaron por definir el concepto de discriminación, o bien se atenían a la definición de los diccionarios ${ }^{37}$. Casi todos los relatores reconocieron que no todo trato diferenciado equivale a discriminación, sino sólo el que no es razonable, es injustificado y perjudicial para la persona. Por lo tanto, las medidas especiales adoptadas a favor de quienes tienen discapacidades físicas, por ejemplo, serían legítimas. En resumen, están permitidas las diferencias que se basan en el mérito, la capacidad o la habilidad individual, pero las clasificaciones fundamentadas en supuestas características de grupo o las estereotipadas no están permitidas.

En fechas más recientes los órganos creados en virtud de los tratados de derechos humanos han interpretado y aplicado las normas en contra de la discriminación y a favor de la igualdad en sentencias, decisiones, comentarios sobre informes estatales y comentarios generales. Los tribunales, al aplicar o enunciar definiciones sobre la discriminación han establecido cuáles grupos de personas están protegidos, la índole de los actos prohibidos o las omisiones, el propósito o

\footnotetext{
34 Ver Theodor Meron, The Meaning and Reach of the International Convention on the Elimination of All Forms of Racial Discrimination, que cita la Restatement of the Foreign Relations Law of the United States (Revised) sec. 702 (que se refiere a la prohibición de la discriminación racial como norma del derecho internacional consuetudinario).

35 Corte IDH. Condición Jurídica y Derechos de los Migrantes Indocumentados. Opinión Consultiva OC-18/03 del 17 de septiembre de 2003. Serie A No. 18.

36 East African Asians v. the United Kingdom, № 4403/70, 14 de dic. de 1973).

37 En su estudio, H. Santa Cruz utilizó la definición que aparece en el Random House Dictionary of the English Language "hacer una distinción a favor o en contra de una persona o cosa conforme al grupo, clase o categoría a la que pertenece la persona o cosa en lugar de su mérito real". Santa Cruz, supra n. 23.
} 
efecto de las medidas adoptadas y cuáles distinciones se consideran aceptables. En los siguientes párrafos, se revisará la jurisprudencia sobre cada uno de estos temas.

\subsection{Distinciones, exclusiones, restricciones o preferencias}

Los órganos de la ONU creados en virtud de tratados comparten un enfoque común en lo relativo al significado de la discriminación. En el párrafo 7 de su Observación General No. 18, el Comité de Derechos Humanos de la ONU define la "discriminación" para los fines del artículo 2 y el artículo 26 del PIDCP en un lenguaje muy similar al empleado en varios otros convenios:

[E]l Comité considera que el término "discriminación", tal como se emplea en el Pacto, debe entenderse referido a toda distinción, exclusión, restricción o preferencia que se basen en determinados motivos, como la raza, el color, el sexo, el idioma, la religión, la opinión política o de otra índole, el origen nacional o social, la posición económica, el nacimiento o cualquier otra condición social, y que tengan por objeto o por resultado anular o menoscabar el reconocimiento, goce o ejercicio, en condiciones de igualdad, de los derechos humanos y libertades fundamentales de todas las personas ${ }^{38}$.

En la práctica, aunque en general se considera que las preferencias otorgadas a los grupos dominantes son discriminatorias, la mayoría de los tratados y la jurisprudencia permiten o incluso exigen que la situación desventajosa de grupos vulnerables o desfavorecidos sea el objetivo de las medidas de acción afirmativa. La idea de tomar en consideración las diferencias pertinentes es bastante antigua. En los casos de África Sudoccidental, la opinión disidente del Juez Tanaka planteó la teoría de base:

El principio de la igualdad ante la ley no significa[...] igualdad absoluta, a saber, el trato igual de los hombres sin considerar las circunstancias individuales y concretas, pero significa[...] igualdad relativa, es decir, el principio de tratar igualmente lo que es igual y desigualmente lo que es desigual. Tratar las materias desiguales en forma diferente de acuerdo con su desigualdad no sólo está permitido sino que es necesario ${ }^{39}$.

En la tercera reunión de la Comisión de Derechos Humanos, Eleanor Roosevelt hizo un señalamiento parecido en el sentido de que la igualdad no implicaba un trato idéntico para hombres y mujeres en todos los asuntos -los beneficios de maternidad, por ejemplo, requieren de un trato diferencial ${ }^{40}$. Tomando este hecho en consideración, una de las versiones preliminares de la DUDH solamente prohíbe "toda discriminación arbitraria". El término "arbitrario" se eliminó porque la mayoría de los delegados estaban de acuerdo que, en derecho, la discriminación se refiere a distinciones dañinas o injustas (arbitrarias) y no a todas las diferenciaciones ${ }^{41}$.

Las acciones afirmativas en favor de individuos o grupos que han sido objeto de discriminación es una forma de reconocer la desigualdad resultante. La Observación General No 4 de la PIDCP establece que "el artículo 3, así como el párrafo 1 del artículo 2 y el artículo 26[...] requiere, no solamente medidas de protección sino una acción positiva destinada a garantizar el disfrute real de los derechos". La Observación General № 18 reconoce, de igual modo, la necesidad de "disposiciones positivas[...] para reducir o eliminar las condiciones que originan

\footnotetext{
38 PIDCP, Observación General 18: No discriminación (1989) en Compilation of General Comments and General Recommendations adopted by Human Rights Treaty Bodies, HRI/GEN/1/Rev. 8, 8 de mayo de 2006, p 185.

39 ICJ Rep. 1966, 4.

40 UN doc. E/CN.4/SR 50, 9.

41 UN docs. E/CN.4/99, E/CN.4/82/add.8 y E/CN.4/SR 52, 6, 8.
} 
o facilitan que se perpetúe la discriminación prohibida por el Pacto". El párrafo 1 del artículo 4 de CEDAW permite la adopción por los Estados Partes de medidas especiales encaminadas a acelerar la igualdad.

Los tribunales internacionales pueden aprobar algunas medidas de acción afirmativa, pero reiteran que tales acciones deben ser razonables, objetivas y proporcionales respecto de las metas. En consecuencia, las acciones positivas suelen ser limitadas en términos de su duración y alcance para hacer frente a las desventajas específicas que padecen ya sea una persona o un grupo. En la Observación General № 23 sobre el artículo 27 del PIDCP, el Comité de Derechos Humanos reconoce que los derechos de las minorías protegidos por el artículo 27 son derechos individuales. Sin embargo, destaca que "[...] puede ser también necesario que los Estados adopten medidas positivas para proteger la identidad de una minoría y los derechos de sus miembros a gozar de su cultura y su idioma perfeccionándolos y a practicar su religión, en común con los otros miembros del grupo" (párrafo 6.2).

En ocasiones las acciones afirmativas son objeto de crítica porque implican una posición contraria a la noción estrictamente formal de la igualdad. También, pues tienden a concentrarse en el trato dado al grupo más que en el que recibe el individuo. En consecuencia, muchos sistemas rechazan las acciones afirmativas inflexibles, tales como las cuotas rígidas, a favor de enfoques centrados más bien en los derechos individuales. No obstante, en varios de sus informes sobre países el Comité de Derechos Humanos del PIDCP ha autorizado el uso de cuotas. Por ejemplo, en sus observaciones finales sobre la India, dio su aprobación a una reforma constitucional que implicaba reservar para las mujeres un tercio de los escaños en las entidades de elección local. Asimismo, aprobó la práctica de reservar puestos de elección popular para miembros de determinadas tribus y castas $^{42}$.

En el ámbito regional, la jurisprudencia europea ha definido la discriminación como la desigualdad de naturaleza arbitraria, o bien como distinciones que carecen de una justificación objetiva y razonable o que tienen un carácter desproporcionado ${ }^{43}$. Los Estados Partes cuentan con un margen de apreciación, pero ciertas bases para la diferencia de trato pueden requerir de razones "particularmente graves" para su justificación ${ }^{44}$. Si la peticionaria comprueba que se ha hecho una distinción, es responsabilidad del Estado demostrar que la diferencia de trato se justifica en términos razonables y objetivos, a saber, que se persigue un fin legítimo y proporcional al mismo. Las distinciones razonables y aquellas diseñadas para fomentar más que para menoscabar la igualdad no son discriminatorias siempre que sean proporcionales al objetivo. En el caso Thlimmenos con Grecia el Tribunal adujo que también hay discriminación "cuando los Estados, sin mediar una justificación objetiva y razonable, no tratan en forma distinta a personas cuyas situaciones son significativamente diferentes" ${ }^{\prime 45}$.

La Convención Americana sobre Derechos Humanos no sólo permite sino que incluso puede exigir medidas positivas para garantizar la igualdad. En su Informe sobre la Situación de los Derechos Humanos en Ecuador en el año 1996, la Comisión Interamericana de Derechos Humanos (CIDH) manifestó:

\footnotetext{
42 UN Doc. PIDCP/C/79/Add.81, párrafo 10.

43 Belgian Linguistic Case, supra n. 31, Sección 1B, párrafo 10.

44 Belgian Linguistic Case, 11 YB. Eur. Conv. H.R. 832 (1968); National Union of Police Case, 18 YB Eur. Conv. H.R. 294 (1975); Sunday Times Case, 30 Eur. Ct. H.R. (ser. A), 2 Eur. H.R.Rep. 245 (1979-1980).

45 Thliemmenos v. Greece, № 34369/97, 6 de abril de 2000, párrafo 44.
} 
"En los lugares donde un grupo ha estado históricamente sometido a formas de discriminación pública o privada, la existencia de disposiciones legislativas puede no ser un mecanismo suficiente para garantizar el derecho de todos los habitantes a la igualdad dentro de la sociedad. Para asegurar el derecho a la igualdad de protección por la ley y ante la misma puede ser necesaria también la adopción de medidas positivas, como la garantía de un tratamiento no discriminatorio en la educación y el empleo, a fin de remediar y proteger contra la discriminación pública y privada".

En su Informe Anual a la Asamblea General de la OEA de 1993, la Comisión se expresó de manera similar, señalando que los principios generales de los artículos 1 y 24 requieren de acción estatal para hacer frente a las desigualdades.

A menudo, el sistema interamericano se ha basado en la jurisprudencia europea sobre discriminación, pero también ha desarrollado su propio enfoque. En el Caso 3/98, Carlos García Saccone con Argentina, la Comisión Interamericana definió el "tratamiento desigual" en lo que respecta al artículo 24 de la Convención Americana como: (i) la negación de un derecho que es reconocido a otros; (ii) la disminución de un derecho a algunos, mientras que es cabalmente otorgado a otros; (iii) la imposición de una obligación a algunos, mientras es menos gravosa con otros; (iv) la imposición de un deber a algunos que no es impuesto de manera tan pesada a otros. Las acusaciones de trato desigual requieren de un estándar de comparación y, en este sentido, la Corte se refirió a un modelo de comparación en la Opinión Consultiva OC-4/84: "[n]o puede afirmarse que exista discriminación en toda diferencia de tratamiento del Estado frente al individuo, siempre que esa distinción parta de supuestos de hecho sustancialmente diferentes y que expresen de modo proporcionado una fundamentada conexión entre esas diferencias y los objetivos de la norma, los cuales no pueden apartarse de la justicia o de la razón, vale decir, no pueden perseguir fines arbitrarios, caprichosos, despóticos o que de alguna manera repugnen a la esencial unidad y dignidad de la naturaleza humana" ${ }^{46}$.

En el caso 73/00, Marcelino Hanríquez et al con Argentina, la Comisión especificó que una distinción implica discriminación cuando: "a) hay una diferencia de tratamiento entre situaciones análogas o similares; b) la diferencia no tiene una justificación objetiva y razonable; c) no hay razonable proporcionalidad entre los medios empleados y el objetivo cuya realización se persigue" [Id. párrafo 37]. La Comisión también ha recurrido a la exigencia del Tribunal Europeo en cuanto a "razones de peso" en lo relativo a la justificación de trato diferente basado en el género. En el Caso 4/01 María Eugenia Morales de Sierra con Guatemala, por ejemplo, la Comisión señaló que:

"[l]as distinciones estatutarias basadas en criterios vinculados a condiciones tales como la raza o el sexo, exigen un escrutinio más intenso. Lo que la Corte y la Comisión Europeas han afirmado también rige para las Américas, es decir, que dado que "el avance de la igualdad de los sexos es hoy un objetivo muy importante,[...] 'tendrían que mediar razones de mucho peso' para justificar una distinción basada únicamente en razones de sexo".

Por su parte, la Corte Interamericana, en su Opinión Consultiva OC-18/03, dejó en claro su opinión de que la Convención Americana obliga a los Estados a adoptar medidas positivas para promover la igualdad, al señalar que:

"[...] los Estados están obligados a adoptar medidas positivas para revertir o cambiar situaciones discriminatorias existentes en sus sociedades, en perjuicio de determinado grupo de personas. Esto implica el deber especial de protección que el Estado debe ejercer con respecto a actuaciones y

46 Corte IDH. Propuesta de Modificación a la Constitución Política de Costa Rica Relacionada con la Naturalización. Opinión Consultiva OC-4/84 del 19 de enero de 1984. Serie A No. 4, párrafo 57. 
prácticas de terceros que, bajo su tolerancia o aquiescencia, creen, mantengan o favorezcan las situaciones discriminatorias" ${ }^{\prime \prime 7}$.

\subsection{Medidas que tengan por objeto o por resultado anular o menoscabar los derechos garantizados}

La mayoría de los tratados, como el artículo 26 del PIDCP, abordan medidas que tienen por objeto O POR RESULTADO el efecto de anular o menoscabar el reconocimiento, goce o ejercicio, en condiciones de igualdad, de los derechos humanos y libertades fundamentales de todas las personas. Por lo tanto, no es necesario demostrar la intención de discriminar y muchos casos se han basado en la disparidad del impacto. En Singh Binder con Canadá, por ejemplo, el Comité de Derechos Humanos determinó que una ley canadiense era indirectamente discriminatoria porque exigía que todos utilizaran cascos de seguridad en determinados empleos, hecho que afectaba negativamente a los Sikhs cuya religión requiere que utilicen turbantes. En última instancia, el gobierno de Canadá logró imponer su punto de vista al demostrar que el trato dispar se justificaba por "ser razonable y estar orientado a propósitos objetivos que son compatibles con el Pacto" 48 .

El enfoque del Tribunal Europeo ante el tema se hizo evidente en el caso de Hugh Jordan con Reino Unido en el que el Tribunal manifestó que: "[e]n los casos en que una política general o una medida tienen un efecto desproporcionadamente perjudicial respecto de un grupo en particular, no se descarta que se considere discriminatoria a pesar de no estar orientada ni dirigida específicamente a dicho grupo" ${ }^{\prime 4}$. No obstante, el Tribunal Europeo no ha determinado la existencia de una violación del artículo 14 a raíz de la disparidad de impacto. En la Opinión Consultiva OC-18/03, la Corte Interamericana también sugirió que el impacto dispar puede entrañar una violación, especificando que "[...] los Estados deben abstenerse de realizar acciones que de cualquier manera vayan dirigidas, directa o indirectamente, a crear situaciones de discriminación de jure o de facto" [OC-18/03, párrafo 103].

En general, sin embargo, pareciera que los Estados pueden promulgar y hacer cumplir medidas uniformes en lo referente a la asignación de beneficios, incluso en casos en que el efecto es dispar en lo referente a ciertos individuos o grupos. El Comité de Derechos Humanos ha indicado que concedería una mayor deferencia a las autoridades estatales cuando se trate de la distribución de recursos económicos, caso en el cual, en su opinión:

"Corresponde al Poder Legislativo de cada país, que es el que mejor conoce las necesidades socioeconómicas de la sociedad considerada, tratar de lograr la justicia social en ese contexto concreto. Salvo que las distinciones hechas sean manifiestamente discriminatorias o arbitrarias, no es de la competencia del Comité evaluar de nuevo esos complejos datos socioeconómicos y sustituir el juicio de los poderes legislativos de los Estados Partes por el suyo" 50 .

En el sistema africano, el texto de los artículos 2 y 3 no se refiere al "propósito o efecto" de las acciones pero la jurisprudencia de la Comisión Africana indica que la indiscriminación directa está prohibida. En el caso de la Association Mauritanienne des Droits de l'Homme v. Mauritania la Comisión Africana señaló que:

\footnotetext{
47 Corte IDH. Condición Jurídica y Derechos de los Migrantes Indocumentados. Opinión Consultiva OC-18/03 del 17 de septiembre de 2003. Serie A No. 18, párrafo 104.

48 Ver también Althammer v. Austria, No 998/2001; Simunek v. Czech Republic, No 516/1992.

49 Hugh Jordan v. United Kingdom, № 24746/94, 4 de mayo de 2001, párrafo 154.

50 Oulajin and Kaiss $v$. the Netherlands, sep. op.
} 
El artículo 2 de la Carta establece un principio fundamental para el espíritu de esta Convención, una de cuyas metas es eliminar todas las formas de discriminación y asegurar la igualdad de todos los seres humanos. Se sustenta en este mismo objetivo la Declaración de los Derechos de las Personas pertenecientes a Minorías Nacionales, Étnicas, Religiosas o Lingüísticas aprobada por la Asamblea General de las Naciones Unidas mediante la resolución 47/135 del 18 de diciembre de 1992 [...]. De lo que antecede, es evidente que el derecho internacional de los derechos humanos y la comunidad de Estados le otorgan cierta importancia a la erradicación de la discriminación en todas sus manifestaciones.

[Com. № 210/98, párrafo 131. El artículo 18(3) también hace referencia a la prohibición de "toda discriminación" en contra de las mujeres, de acuerdo con las declaraciones y convenios internacionales].

Los tribunales internacionales han ampliado, asimismo, los derechos incluidos en la garantía de no discriminación. En los casos Broeks y Zwaan-de Vries, el Comité de Derechos Humanos acordó que el artículo 26 del PIDCP no se limita a garantizar la igualdad respecto de los derechos civiles y políticos asegurados por el Pacto. Por lo tanto, si bien el Pacto no exige que los Estados promulguen leyes de seguridad social, al aprobarse la legislación de esta naturaleza en el ejercicio de la autoridad soberana de un Estado, dicha legislación debe cumplir con las garantías de igualdad de derechos que establece el artículo 26 del Pacto ${ }^{51}$. La Observación General No 18 del Comité explica que el artículo 26 establece un derecho autónomo al prohibir la discriminación de hecho o de derecho en cualquier área regulada y protegida por las autoridades. Dicho de otro modo, el PIDCP requiere que todo derecho o beneficio otorgado mediante legislación sea concedido sin discriminación, aun cuando el Estado no tenga la obligación legal de proporcionar tales derechos o beneficios.

\subsection{Medidas con base en la identificación con un grupo específico}

Las cláusulas de prohibición de discriminación identifican como inaceptables determinadas distinciones: las motivadas por raza, color, sexo, idioma, religión, opiniones políticas o de otra índole, origen nacional o social, posición económica, nacimiento o cualquier otra condición. El artículo 26 del PIDCP no contiene una enumeración taxativa considerando que agrega "cualquier otra condición" a la lista de razones prohibidas para la discriminación. En el caso 196/1983, Gueye con Francia, por ejemplo, el Comité de Derechos Humanos sostuvo que, si bien el PIDCP no se refería explícitamente a la nacionalidad, la discriminación basada en ese factor quedaba prohibida por los términos "otra condición" señalados en los artículos 2 y 26.

Los peticionarios que presenten demandas en virtud del Protocolo Opcional al PIDCP deben aducir que la diferencia de trato es atribuible a su condición de miembros de un grupo identificable y definido ${ }^{52}$. Esto no es lo mismo que una acción arbitraria o abuso de la discrecionalidad

51 S.W.M. Broeks v. Neth., № 172/1984, párrafo 12.4. El Comité ha ampliado las disposiciones del artículo 26 e incluido otros beneficios económicos y sociales tales como diversos tipos de pensiones (Danning v. Netherlands, 180/1984, Gueye v. France, 196/1985, Pauger v. Austria, 415/1990, Pepels v. Netherlands, 484/1991, Hoofdman v. Netherlands, 602/1994, Johannes Vos v. Netherlands, 786/1997); beneficios de desempleo y educacionales (Broeks v. Netherlands, 172/1984, Hendrika Vos v. Netherlands, 218/1986, Blom v. Sweden, 191/1985, Lindgren v. Sweden, 198-199/1988, Waldman v. Canada, 694/1996); derechos de propiedad (Adam v. Czech Republic, 586/1994); laborales (Sprenger v. Netherlands, 395/1990) e indemnización por despido, Valenzuela v. Peru 209/1988).

$52 B d B$ v. Netherlands, 272/1989. Los grupos reconocidos que corresponden a la categoría "cualquier otra condición" incluye a los abuelos, estado civil, nacionalidad, ciudadanía, edad, desempleo, y el hecho de ser o no abogado. Ver, por ejemplo, Danning v. Netherlands, 180/1984; Sprenger v. Netherlands, 395/1990, Hoffdman v. Netherlands, 602/1994, Gueye v. France, 196/1985, Griffin v. Spain, 493/1992, Adam v. Czech Republic, 496, 1994, Jong v. Netherlands, 855/1999, Oulajin \& Kaiss v. Netherlands, 406, 426/1990, Gomez v. Spain, 865/1999. Asimismo, el Comité ha señalado que la orientación sexual y la ilegitimidad están incluidas en las categorías anteriores. 
cuando se hacen distinciones entre individuos ${ }^{53}$. La discrecionalidad en materias judiciales, por ejemplo, se puede ejercer de manera arbitraria o abusiva, sin que necesariamente constituya discriminación. En consecuencia, el Comité de Derechos Humanos determinó que no había discriminación en el caso № 272/1989, B con Países Bajos, en que una agencia pública administrativa notificó a ciertos fisioterapeutas acerca de obligaciones relacionadas con los seguros sin notificar a todos. El Comité señaló que los autores "no han manifestado que el trato diferencial se podía atribuir al hecho de pertenecer a una categoría claramente diferenciada que podría haber implicado discriminación en relación con cualquiera de las razones aducidas o la situación de 'otra condición' señalada en el artículo 26". Esto no quiere decir que no se violaron derechos: es posible que la situación implique cuestiones de debido proceso o el derecho a medidas de reparación con motivo de una acción administrativa arbitraria. Esta forma de ejercer la discreción puede ser objeto de análisis y requerir una justificación, sin que por ello constituya discriminación.

Determinar la existencia de discriminación requiere la identificación de los grupos de referencia adecuados. En el caso Ballantyne et al con Canadá, Nºs. 359/1989 y 385/1989, habitantes anglófonos de Quebec adujeron que las leyes sobre idiomas de Quebec, que prohíben la existencia de anuncios comerciales en las tiendas en cualquier idioma que no sea el francés, violaba el artículo 26 y discriminaba en contra de ellos por razones de idioma. El Comité comparó la situación de los peticionarios con la de las personas francófonas en Quebec y determinó que no había discriminación porque la restricción sobre el uso del francés regía de igual forma para ambos grupos; sin embargo, el Comité no examinó el efecto dispar de la medida sobre los propietarios anglófonos de tiendas quizás porque, en términos generales, los ciudadanos anglófonos son mayoría en Canadá ${ }^{4}$.

Algunas distinciones son particularmente problemáticas. Por ejemplo, las diferencias en cuanto a leyes y prácticas al interior de los estados federales han sido cuestionadas por considerarlas discriminatorias por quienes residen en un Estado o territorio cuyas leyes son desfavorables en comparación con las de otra unidad federal. En el caso Hesse con Australia, el Comité de Derechos Humanos del PIDCP determinó que las diferencias entre los Estados australianos en cuanto a la duración de las leyes de prescripción no eran razón suficiente para sustentar un reclamo de discriminación. En cambio, la Comisión Interamericana de Derechos Humanos determinó en el caso Roach y Pinkerton con Estados Unidos Res. 3/87, Caso № 9647, que la disparidad en las leyes sobre sentencias para delincuentes juveniles en los diferentes Estados de los Estados Unidos constituye una discriminación ilícita.

Las demandas de discriminación basadas en cuestiones de nacionalidad y de discriminación religiosa han demostrado ser particularmente conflictivas. En cuanto al primer tema, ciertos derechos, entre los que se cuenta el derecho no menor de ingresar y permanecer en un país, puede limitar a los nacionales de un estado en particular. Tanto el CIEDR como ICESCR tienen disposiciones generales sobre los derechos de los extranjeros. El artículo 1(2) de CIEDR establece que la Convención -en su totalidad- no se puede aplicar a distinciones, exclusiones, restricciones o

\footnotetext{
53 Ver Gauthier v. Canada, 633/1995 y Tufyal Choudhury, Interpreting the Right to Equality under Article 26 of the International Covenant on Civil and Political Rights, 2003 E.H.R.L.R. 1.

54 El Comité determinó que había una violación del artículo 19 (libertad de expresión) afirmando, además, que los peticionarios no podían exigir los derechos de las minorías lingüísticas en virtud del artículo 27 del PIDCP porque, considerando el país en su conjunto, los habitantes anglófonos eran mayoría. Comparar con Diergaardt v. Namibia, № 760/1997, caso en el cual los peticionarios adujeron que el hecho de que el gobierno de Namibia no hubiera promulgado leyes que permitieran el uso de idiomas oficiales distintos del inglés les negaba el uso de su lengua materna en la vida pública, hecho que violaba el artículo 26. El Comité concordó que la acción del Estado afectaba a los hablantes de Afrikaans en forma desproporcionada y constituía una violación del artículo 26.
} 
preferencias que un Estado Parte haga entre nacionales y extranjeros, pero el artículo 1(3) descarta identificar una nacionalidad en particular en lo referente a trato discriminatorio por razones de nacionalidad, ciudadanía o nacionalización. En el caso B.M.S. con Australia, CIEDR supuso que una distinción orientada a un grupo específico de extranjeros o que tuviera un efecto adverso sobre los mismos constituía una violación de la Convención.

EI PIDCP se aplica a "todas las personas" a menos que se especifique lo contrario, como ha recalcado el Comité de Derechos Humanos en su Observación General № 15 . No obstante, el artículo 25 del PIDCP permite que los Estados limiten los derechos políticos de los extranjeros mientras que se garantiza la libertad de movimiento solamente a quienes se encuentren "legalmente" en un país determinado. El artículo 13 protege a los extranjeros contra el trato arbitrario y establece que un extranjero con residencia legal en el territorio de un Estado Parte puede ser expulsado del mismo solamente como consecuencia de una decisión adoptada conforme a la ley. Salvo en casos en que razones imperiosas de seguridad nacional determinan un trato diferente, se debe permitir que los extranjeros presenten sus motivos para defenderse de la expulsión, a contar con representación y a contar con la posibilidad de la revisión de su caso por parte de una autoridad competente.

En sus observaciones finales sobre los informes periódicos presentados por los Estados, el Comité de Derechos Humanos criticó algunas prácticas implementadas por los Estados que son discriminatorias por motivos de nacionalidad, las cuales incluyen distinciones entre quienes son ciudadanos por nacimiento y las personas nacionalizadas ${ }^{55}$, requisitos para extranjeros que no se aplican a sus nacionales ${ }^{56}$, y criterios estrictos para la obtención de la ciudadanía que discriminan en contra de residentes permanentes que pertenecen a grupos minoritarios o son extranjeros ${ }^{57}$. Otras medidas objetadas incluyen el no otorgamiento de la nacionalidad a apátridas nacidos en el Estado, el hecho de despojar de su ciudadanía a quienes critican al gobierno, las expulsiones masivas de los no nacionales y las reglas discriminatorias que perjudican a las mujeres en la transmisión de la nacionalidad a sus hijos ${ }^{58}$. En general, los tribunales concuerdan que si bien la nacionalización es una prerrogativa del Estado, debe otorgarse sobre la base de criterios objetivos y en un plazo razonable, particularmente en el caso de personas que han vivido en un Estado determinado por muchos años.

El Comité de Derechos Humanos ha analizado casos de discriminación basados en la nacionalidad u "origen nacional" en el contexto (i) laboral ${ }^{59}$, (ii) la posición económica ${ }^{60}$, (iii) el derecho a voto, (iv) la tributación y seguridad social, (v) las pensiones ${ }^{61}$ y (v) la inmigración. En estos casos, no se puede invocar "la mera inconveniencia administrativa" para justificar el trato desigual y tampoco son válidas las diferencias en cuanto a las circunstancias económicas, sociales o financieras. La

55 Ireland ICCPR A/48/40.

56 Japan, ICCPR, A/49/40.

57 Latvia, ICCPR, A/50/40. Entre los ejemplos de criterios discriminatorios se incluyen un requisito respecto del idioma que ningún extranjero puede cumplir (por ejemplo, Estonia, ICCPR, A/51/40).

58 En sus comentarios finales sobre los informes estatales el PIDESC ha criticado las leyes que impiden a una mujer transmitir su nacionalidad a sus hijos o que privan a las mujeres de su nacionalidad original al contraer matrimonio con extranjeros. Ver, por ejemplo, Egypt, ICESCR, E/2001/22 (2001) 38, párrafos 159 y 175; y Jordan, ICESCR, E/2001/22 (2000) 49, párrafo 234.

59 Karakurt v. Austria, № 965/2000.

60 Adam v. Czech Republic, № 586/1994; Simunek v. Czech Republic, No 516/1992, Blazek et al v. Czech Republic, No 857/1999, y Des Fours v. Czech Republic, No 747/1997, Drobek v. Slovakia, No 643/1995, Malik v. Czechoslovakia, No 669/1995, y Schlosser v. Czech Republic, No 670/1995.

61 En Gueye et al v. France, № 196/85. 
deportación de trabajadores migratorios que han vivido y trabajado en un Estado por mucho tiempo también ha sido objeto de críticas $^{62}$. El Tribunal Europeo de Derechos Humanos ha condenado asimismo la discriminación basada en la nacionalidad ${ }^{63}$, Ilegando a la conclusión de que se requiere la presentación de "razones de mucho peso" antes de poder considerar que el trato diferencial debido a la nacionalidad cumple con las disposiciones del Convenio Europeo ${ }^{64}$.

La Comisión Africana ha sido escéptica frente a los cambios en las leyes sobre nacionalidad y la aplicación de las mismas para privar a las personas de su nacionalidad. En la Com. № 97/93, John K. Modise con Botswana, la Comisión Africana resolvió que la privación de la ciudadanía del peticionario por parte de Botswana le negaba el derecho de igualdad de acceso a los servicios públicos del país garantizados en virtud del artículo 13(2) de la Carta de la ONU65. En la Com. 159/96, UIDH, FIDH y otros con Angola, la Comisión Africana señaló que la expulsión masiva de cualquier categoría de personas, fuera por razones de nacionalidad, religión, origen étnico o racial u otras consideraciones "constituyen una especial violación de los derechos humanos"66. La Comisión manifestó, asimismo, que "una acción de gobierno dirigida especialmente a un grupo específico de carácter nacional, racial, étnico o religioso generalmente es considerada como discriminatoria en el sentido de que ninguna de sus características tiene base legal alguna[...]" [Id. párrafo 15].

En su Opinión Consultiva OC-18/03 del año 2003, la Corte Interamericana de Derechos Humanos analizó a fondo el tema de la discriminación dirigida contra trabajadores migratorios extranjeros. Según la Corte Interamericana, las obligaciones de un Estado respecto de los derechos humanos incluyen el deber de ejercer acción afirmativa, evitar tomar medidas que restringen o violan un derecho fundamental, además de eliminar las medidas y prácticas que restringen o violan algún derecho básico. La obligación general de respetar y garantizar el ejercicio de los derechos es un deber que se impone a los Estados en beneficio de las personas que se encuentran bajo sus respectivas jurisdicciones, independientemente de la situación migratoria de los protegidos. La Corte señaló, además que:

"Los Estados, por lo tanto, no pueden discriminar o tolerar situaciones discriminatorias en perjuicio de los migrantes. Sin embargo, sí puede el Estado otorgar un trato distinto a los migrantes documentados con respecto de los migrantes indocumentados, o entre migrantes y nacionales, siempre y cuando este trato diferencial sea razonable, objetivo, proporcional, y no lesione los derechos humanos" [Id. párrafo 119].

62 Ver, por ejemplo, República Dominicana, ICESCR, E/1991/23 (1990) 55, párrafo 249; y Nigeria, ICESCR, E/1999/22 (1998) 27, párrafo 105.

63 Ver, por ejemplo Gaygusuz v. Austria № 17371/90, 16/09/1996.

64 Ver también: Koua Poirrez v. France (№ 40892/98, 30/09/2003); John Murray v. the United Kingdom, № 18731/91, 08/02/1996 y Moustaquim v. Belgium, No 12313/86, 18/02/1991.

65 Legal Resources Foundation v. Zambia, Com. 211/98 tuvo por resultado el que la Comisión determinara que había una violación, en este caso del artículo 2, debido al proyecto de una nueva disposición constitucional que exigía que cualquier persona que deseara asumir como Presidente demostrara que ambos padres eran de Zambia, ya fuera por nacimiento o ascendencia. La Comisión Africana dejó en claro que cualquier medida que intente excluir a un segmento de los ciudadanos de la participación en el proceso democrático, como se intentaba con esta reforma constitucional, es discriminatoria y constituye una violación de la Carta de la ONU.

66 Ver también OMCT and others v. Rwanda, Com. Nos. 27/89, 46/91, 49/91, 99/93. En RADDHO v. Zambia Com. 71/92, la forma en que se realizaron las expulsiones constituía una violación de la Carta de la ONU. La Comisión señaló que "las expulsiones simultáneas de los nacionales de muchos países no invalida la acusación de discriminación. Por el contrario, el argumento de que tantos extranjeros fueron objeto del mismo trato equivale a un reconocimiento de violación del artículo 12(5)". Id. párrafo 25. 
"[L]a calidad migratoria de una persona no puede constituir, de manera alguna, una justificación para privarla del goce y ejercicio de sus derechos humanos, entre ellos los de carácter laboral" [Id. párrafo 134].

La opinión sugiere mayores derechos y las correspondientes obligaciones estatales que las que probablemente existen en las leyes y las prácticas de la mayoría de los Estados.

El tema de la discriminación religiosa también es problemático porque el deseo de practicar o manifestar sus creencias religiosas suele llevar a los individuos a pedir exenciones en cuanto a leyes que aparentemente son neutrales. Es sumamente difícil distinguir entre el cumplimiento aceptable de leyes cuya aplicación uniforme constituye una necesidad legítima y aquellas cuyo cumplimiento equivale a una discriminación injustificada en contra de una religión en particular porque sus creencias diferentes le dan el derecho a recibir un trato distinto.

Los reglamentos gubernamentales de carácter neutral -aquellos que no exigen la adhesión a la religión en general o a una religión específica en particular- debieran ser válidos, por lo general, para todos los integrantes de la sociedad. Sin embargo, es necesario reconocer ciertas exenciones o ajustes mediante los cuales se puede servir a los intereses del gobierno por otros medios y en los casos en que las exigencias legales son particularmente graves para los objetores de conciencia ${ }^{67}$. Pueden surgir temas difíciles cuando las actividades normales o los requisitos de una escuela, por ejemplo los códigos de vestimenta, obligan al alumno a comportarse de manera que es contraria a sus creencias religiosas. El Estado tiene un interés legítimo en que su programa educativo sea coherente e integral. Si las creencias religiosas producen como resultado una búsqueda de exenciones que impliquen una alteración substancial del programa educativo o si interfieren con los derechos de otros alumnos, las autoridades tienen el derecho legítimo de determinar que la exención no se justifica, particularmente si existen alternativas educacionales que cumplan con las normas religiosas del alumno. No obstante, las garantías de igualdad y no discriminación en materia de religión y creencias pueden significar que todos tienen derecho a un grado razonable de ajuste en el lugar de trabajo, en el servicio militar o el servicio alternativo, en las escuelas y cárceles, para manifestar su religión o sus creencias.

Lograr un acomodo adecuado puede implicar un reconocimiento de la discriminación indirecta o bien de acciones basadas en los prejuicios religiosos ${ }^{68}$. En Thlimmenos con Grecia, demanda No 34369/97, del 6 de abril del 2000, el Tribunal Europeo sostuvo que la legislación griega era discriminatoria en virtud de cuestiones religiosas. Las autoridades griegas se habían negado a nombrar al peticionario, un Testigo de Jehová, como contador colegiado porque anteriormente había sido objeto de una condena criminal por negarse a usar el uniforme militar de Grecia. El peticionario demostró que su rechazo al uso del uniforme militar se debía a su carácter de objetor de conciencia ya que los Testigos de Jehová están comprometidos con el pacifismo. El Tribunal determinó que las leyes griegas lo habían tratado igual que cualquier otro criminal siendo que su condena provenía del ejercicio de su libertad de credo religioso; el hecho de que la ley no estableciera una diferencia era discriminatorio.

Otros problemas se originan debido a leyes que regulan a las religiones y su relación con el Estado. Algunas Constituciones nacionales establecen el predominio de una religión específica concediéndole privilegios que no se otorgan a otras religiones o a los no creyentes, lo cual plantea cuestiones relacionadas con la igualdad y la no discriminación. A la inversa, en ocasiones,

\footnotetext{
67 Ver: Cha'are Shalom Ve Tsedek v. France, Comm. № 27417/95, 7 de abril de 1997.

68 Ver, por ejemplo, Hoffmann v. Austria, № 12875/87, 23 de junio de 1993; Palau-Martinez v. France, № 64927/01, 16 de diciembre de 2003.
} 
los gobiernos reprimen actividades religiosas, determinando que nadie puede invocar la libertad religiosa si es contraria a las leyes seculares. La jurisprudencia internacional ha reconocido que la existencia de una religión establecida o religión oficial del Estado puede producir discriminación en contra de otros grupos religiosos. En la Com. № 694/1996, Waldman con Canadá, el Comité de Derechos Humanos sostuvo que, cuando un Estado Parte opta por otorgar financiamiento público a escuelas religiosas, dicho financiamiento debe proporcionarse sin discriminación. En el caso de la Iglesia Católica de la Canea con Grecia, demanda № 25528/94, del 16 de diciembre de 1997, el Tribunal Europeo de Derechos Humanos dictaminó también que se violaba el artículo 14 (no discriminación) entendido en conjunto con el párrafo 1 del artículo 6 (derecho a una audiencia justa) porque tanto la Iglesia Griega Ortodoxa como la comunidad judía tenían personería legal que les permitía proteger sus derechos de propiedad bajo la ley griega, pero la Iglesia Católica Romana no gozaba de estos derechos y no existía una justificación objetiva y razonable para que fuera tratada de forma diferente.

\subsection{Medidas arbitrarias, poco razonables, desproporcionadas o injustificadas}

No todas las distinciones que existen conforme a la ley o en la práctica son injustificadas. Las restricciones relacionadas con la edad quizás sean las que con mayor frecuencia se consideran razonables ${ }^{69}$. En la Comunicación N ${ }^{\circ}$ 24/1977, Lovelace con Canadá, una ley canadiense imponía un trato diferente a hombres y mujeres en igualdad de circunstancias, privando así a la peticionaria de su condición de "indígena" y los beneficios que esta situación implica, por el hecho de haber contraído matrimonio con alguien que no era indígena. El Comité de Derechos Humanos estimó que la medida establecía una discriminación de jure basada en el sexo y se dedicó a determinar si dicha interferencia estaba justificada. El Comité señaló que las distinciones "deben tener una justificación razonable y objetiva y ser compatibles con las demás disposiciones del Pacto, considerado en su conjunto" [ld, párrafo 16]. Tomando en cuenta que la intención manifiesta de la parte pertinente de la Ley Indígena (Indian Act) era conservar la identidad de la tribu y el matrimonio de Lovelace se había disuelto, el Comité determinó que negarle el derecho a residir en la reserva no era razonable, porque no era necesario para preservar la identidad de la tribu ${ }^{70}$.

Las opiniones acerca de la índole razonable de las distinciones puede ir cambiando con el tiempo y esta subjetividad inherente ha ocasionado cierta incoherencia en la jurisprudencia. En la demanda No 295/1988, Järvinen con Finlandia, por ejemplo, el peticionario adujo que la nueva ley finlandesa que exigía que los objetores de conciencia realizaran un servicio civil alternativo de 16 meses de duración -en comparación con los 8 meses que dura el servicio militar- discriminaba en su contra sobre la base de sus creencias filosóficas. El Comité determinó que la prolongación del período en el caso del servicio civil alternativo se basaba en criterios razonables y objetivos pero en el Nº 666/1995, Foin con Francia, el Comité cambió su criterio, resolviendo que un plazo

\footnotetext{
69 Ver, por ejemplo, Love v. Australia, № 983/2001; Schmitz-de-Jong v. the Netherlands, № 855/1999.

70 Para información sobre otros casos en los que se evalúa si son razonables las medidas que establecen distinciones basadas en el sexo, ver: Broeks v. the Netherlands, $N^{\circ}$ 172/1984, Zwaan de Vries v. the Netherlands, $N^{\circ} 182 / 1984$, Pauger v. Austria, No 415/1990 y Johannes Vos v. the Netherlands, № 786/1997, en las que el Comité manifestó que las distinciones basadas en el sexo en las leyes de seguridad social no cumplían propósitos razonable ni objetivos y por lo tanto violaban el artículo 26 de PIDCP. Ver también: Avellanal v. Perú, No 202/1986 (que señala que una ley peruana que impide que las mujeres casadas representen el patrimonio conyugal frente a los tribunales es una violación del artículo 26); Young v. Australia, № 941/2000 (el Estado no había logrado demostrar motivos razonables y objetivos que justificaran el trato desigual de parejas del mismo sexo en comparación con las parejas heterosexuales no casadas) y el caso de las Mujeres de la República de Mauricio, № 35/1978 (ley de inmigración de Mauricio que establecía límites a los derechos de residencia de los maridos extranjeros pero no así para las esposas extranjeras de los hombres de Mauricio, es decir, discriminación basada en el género).
} 
más largo de servicio alternativo para los objetores de conciencia constituía una violación del artículo 26 por razones de opinión, con lo que rechazó el argumento del Estado que la duplicación del período de servicio era la única manera de comprobar la sinceridad de las convicciones de una persona ${ }^{71}$.

\section{El significado de la discriminación}

Considerando lo analizado hasta aquí, se podría llegar a la conclusión de que la discriminación implica una distinción de cualquier tipo (exclusión, preferencia, limitación o restricción) entre personas o grupos que se encuentran en situaciones similares, a menos que exista una justificación objetiva y razonable y el grado de la distinción sea proporcional al objetivo. El principio de igualdad es el aspecto positivo de esta prohibición, pero plantea la cuestión de si la obligación tiene que ver con la igualdad de oportunidades o bien de resultados iguales, con sus consecuencias redistributivas. Aparentemente, el Comité para la Eliminación de la Discriminación Racial asumió la segunda posición al decidir que la Convención está dirigida a garantizar el disfrute efectivo de la igualdad en la práctica ${ }^{72}$. En la medida que el objetivo es la igualdad de facto, una de las consecuencias es que se requiera de una motivación discriminatoria, sino que baste la prohibición de la disparidad de impacto. Estas exigencias respecto de la igualdad de resultados también podrían hacer necesario abordar injusticias históricas que generaron los patrones sistémicos de desigualdad.

Además de la discriminación directa e indirecta podría plantearse el requisito de que, dentro de lo razonable, los Estados proporcionen el espacio necesario para acomodar las diferencias mediante una modificación de las leyes y prácticas con el fin de permitir que las personas que reúnen los requisitos puedan postular, realizar las funciones esenciales y disfrutar de los beneficios y privilegios a los que tienen acceso los demás. El requisito de encontrar un ajuste para las diferencias se ha presentado con mayor frecuencia en el área de las discapacidades.

El principio de igualdad no excluye las distinciones y éstas no equivalen a una discriminación injusta en casos en que las (1) diferenciaciones se basan en cuestiones de carácter y conducta consideradas como cuestiones de opción individual (por ejemplo, ser honrado, prudente, trabajador, desempeñarse en forma ética, etc.) o las (2) las diferenciaciones se basan en llevar a la práctica ciertos valores sociales imperiosos y contradictorios aun cuando las características individuales correspondientes son innatas y no una cuestión de opción individual (la fuerza física en el caso de los bomberos, por ejemplo). En consecuencia, los empleadores pueden discriminar legalmente conforme a ciertas características personales tales como la raza y la religión en circunstancias determinadas cuando éstas son fundamentales para el trabajo a desempeñar.

Sobre la base de estos conceptos, en la redacción del artículo 26 del PIDCP se ratificó que la igualdad no requiere de un trato idéntico y permite, en cambio, "diferenciaciones razonables" entre individuos o grupos de individuos fundadas en razones pertinentes y significativas ${ }^{73}$. Anteriormente, la Secretaría de la ONU presentó memorandos a la ex Subcomisión de la ONU de Prevención de Discriminaciones y Protección de las Minorías, la cual definió la discriminación de manera similar señalando que incluye "toda conducta basada en una distinción fundamentada

\footnotetext{
71 Ver también H.A.E.D.J. v. the Netherlands ( $\mathrm{N}^{\circ}$ 297/1988, ICCPR); R.T.Z. v. the Netherlands $\mathrm{N}^{\circ}$ 245/1987; M.J.G. v. the Netherlands No 267/1987, y Drake and Julian v. New Zealand (Nº 601/1994).

7233 UN GAOR Supp. (No 18), 108, 110, UN Doc. A/33/18 (1978).

73 Anexos de 10 GAOR, UN Doc. A/2929 párrafo 34 (1955).
} 
en categorías naturales o sociales, que no tenga relación alguna con las capacidades o méritos individuales ni con el comportamiento específico de la persona" ${ }^{\prime 74}$.

Gran parte de esta definición plantea una cuestión de principio acerca de cuáles son las diferencias pertinentes para determinar la necesidad de igual trato. Madagascar ha afirmado que el esposo y la esposa son diferentes y que las "prerrogativas" que se le conceden al marido durante el matrimonio "le otorgan unidad y dirección al hogar" ${ }^{75}$. Históricamente, los Estados y las culturas han utilizado las diferencias físicas entre hombres y mujeres como bases legítimas para el trato desigual en el área del derecho y de las políticas. En el caso Van der Mussele con Bélgica ${ }^{76}$, el abogado del peticionario alegó discriminación debido a la obligación de trabajar sin recibir remuneración, un deber que no se impone a otras profesiones. El Tribunal sostuvo que existen diferencias fundamentales entre las profesiones en cuanto a su situación legal y la naturaleza de las funciones involucradas, lo que genera diferencias en las situaciones. Por lo tanto, no había discriminación en este caso.

Las visiones sociales necesariamente impactan la jurisprudencia sobre la discriminación. En Hoffman con Austria ${ }^{77}$, una decisión de 5 votos contra 4 del Tribunal Europeo de Derechos Humanos consideró si la denegación de custodia a una peticionaria por motivo de su religión (Testigo de Jehová) constituía una discriminación inadmisible basada en la religión o si era una distinción legítima fundada en la prueba independiente de los mejores intereses de los niños. El Tribunal sostuvo que había tanto una distinción como un objetivo legítimo, pero que la medida era desproporcionada y, por lo tanto, era una discriminación inadmisible. Existió una fuerte disidencia que argumentó que la determinación del interés superior de los niños debía ser entregado a la determinación estatal. El Comité de Derechos Humanos ha dejado en claro que las concepciones tradicionales sobre los roles de género en el trabajo y el hogar no justifican la discriminación. En el caso Broeks con los Países Bajos (No 172/1984, PIDCP) el Comité de Derechos Humanos determinó que la denegación de los beneficios de seguridad social a la Sra. Broeks, en su calidad de mujer casada, en igualdad de condiciones con los de un hombre casado, constituía discriminación en virtud del artículo 26 del PIDCP. El Comité de Derechos Humanos señaló que, conforme a la ley correspondiente de los Países Bajos, para recibir compensación por desempleo, una mujer casada tenía que demostrar que era el sostén de la familia, condición que no se aplicaba a los hombres casados. Dicha diferenciación colocaba a las mujeres casadas en situación de desventaja frente a los hombres casados.

Las opiniones sobre la ilegitimidad y la homosexualidad han cambiado en muchas sociedades con lo que las distinciones basadas en estos factores son ahora menos aceptables. Se rechazan las distinciones entre los hijos nacidos dentro o fuera del matrimonio para fines relacionados con la herencia ${ }^{78}$ y lo mismo sucede con la diferencia entre hijos legítimos e ilegítimos en lo referente a los derechos de acceso del padre ${ }^{79}$. El trato diferencial basado en la orientación sexual ha sido

\footnotetext{
74 UN Doc. E/CN.4/Sub.2/40, párrafos 33-36 (1949). Un memorando anterior manifestaba que la discriminación implica un trato desigual y desfavorable, ya sea mediante el otorgamiento de beneficios o la imposición de cargas, en virtud de fundamentos inadmisibles. Definitions of the Expressions "Prevention of Discrimination" and "Protection of Minorities" (Memorandum by the Division of Human Rights), UN Doc. E/CN.4/Sub.2/8, 2 (1947).

75 UN Doc. A/33/40, 33 GAOR Supp. 40, párrafo 290 (1978).

7670 Eur. Ct.H.R. (Ser. A) 23 Nov. 1983, 6 EHRR 163 (1983).

77 255-C Eur. Ct. H.R. (Ser. A), 23 de junio de 1993, 17 EHRR 293 (1994).

78 Marckx v. Belgium, 31 Eur. Ct.H.R. (Ser. A), 13 de junio de 1979, 2 EHRR 330 (1979-80); Inze v. Austria, 126 Eur. Ct. H.R (Ser. A), 28 de octubre de 1987, 19 EHRR 394 (1988).

79 Sahin v. Germany (GC), sentencia del 8 de julio de 2003, 36 EHRR 43 (2003); Sommerfeld v. Germany, sentencia del 8 de julio de 2003, 38 EHRR 35 (2004).
} 
considerado discriminatorio en algunas circunstancias ${ }^{80}$ pero no cuando el tema se refiere a la adopción de un hijo y el Estado la rechaza debido al "estilo de vida" del peticionario ${ }^{81}$. Al parecer, la determinación de lo que constituye una diferenciación razonable y pertinente no puede decidirse sin referencia a otros valores sociales que evolucionan con el tiempo. Aquello que constituye una distinción adecuadamente "justa" está determinado por los estándares actuales, si estos son universales, regionales, o nacionales, aún está por resolverse.

En un estudio reciente sobre brechas en el Derecho Internacional de los Derechos Humanos en materia de discriminación, un grupo de estudio nombrado por el Consejo de Derechos Humanos de la ONU estableció que determinados grupos estaban en situación de subprotección: grupos religiosos, refugiados, solicitantes de asilo, apátridas, trabajadores migrantes, personas desplazadas dentro del país, comunidades basadas en la ascendencia, pueblos indígenas, minorías, y personas sometidas a la ocupación extranjera ${ }^{82}$.

Un breve examen de varios casos en el sistema europeo relacionado con personas de origen Roma indica la necesidad de una evaluación más profunda de lo que constituye discriminación y cuáles distinciones son admisibles. En el Reino Unido se han presentado una serie de alegatos por parte de migrantes ("viajeros" y personas de origen Roma) señalando que la legislación territorial y su ejecución por parte de las autoridades locales de dicho país en contra de la ocupación de terrenos por estos grupos equivalen a discriminación racial ${ }^{83}$. A pesar del evidente impacto negativo de las leyes de planificación, se consideró admisible la intervención respecto de los derechos de los peticionarios como proporcional a la medida de cumplir con el objetivo legítimo de conservar el medio ambiente. El Tribunal no le asignó gran peso a las acusaciones de discriminación sistemática en contra de los miembros del grupo.

Al parecer, la noción de discriminación efectivamente ha evolucionado desde una "percepción de discriminación como un trato principalmente desfavorable dirigido a un segmento de la comunidad hacia un concepto más amplio que incluye tanto la diferenciación no intencional o incluso la tradicional y, en épocas más recientes, el reconocimiento de que la discriminación puede ser

80 En Toonen v. Australia, № 488/1992, el Comité de Derechos Humanos determinó que las leyes de Tasmania que penalizaban las relaciones sexuales consensuales entre hombres violaba el derecho a la privacidad de Toonen, garantizada por el PIDCP. El Comité de Derechos Humanos señaló (párrafo 8.7) que la referencia al "sexo" en los artículos 2(1) y 26 del PIDCP incluía la orientación sexual. En Young v. Australia, № 941/2000, el Comité declaró que la orientación sexual quedaba amparada por los fundamentos de "cualquier otra condición" señalados en el artículo 26 del PIDCP, más que un aspecto relacionado con el sexo. Ver también, Joslin v. New Zealand, № 902/1999. Para casos del Tribunal Europeo, ver por ejemplo: $L$ and $V$ v. Austria, sentencia del 9 de enero de 2003; Karner $v$. Austria, sentencia del 24 de julio de 2003, 38 EHRR 24 (2004); B.B. v. the United Kingdom, № 53760/00, sentencia del 10 de Oct. de 2004; Smith and Grady v. the United Kingdom, Nos. 33985/96 y 33986/96, sentencia del 27 de Sept. de 1999; y Lustig-Prean and Beckett v. the United Kingdom, Nos. 31417/96 y 32377/96, sentencia del 27 de Sept. de 1999). Este último caso representa la consideración más clara del cambio en las actitudes de la sociedad. Eur.Ct.H.R. estimó que no se podía hacer caso omiso de las opiniones generales y en constante desarrollo como tampoco de los cambios legales en las leyes internas de los Estados contratantes en favor de permitir el ingreso de homosexuales a las Fuerzas Armadas de dichos Estados. En consecuencia, el gobierno del Reino Unido no había presentado razones convincentes y de peso para justificar la baja de los peticionarios, hecho que era una consecuencia directa de su homosexualidad. Ver también Beck, Copp and Bazeley v. the United Kingdom, Nos. 48535/99, 48536/99 y 48537/99, 22 de Oct. de 2002 y Perkins and R v. the United Kingdom, Nos. 43208/98 y 44875/98, 22 de Oct. de 2002.

81 Frette v. France, sentencia del 26 Feb. 2002, 38 EHRR 21 (2004), pero ver también: Salgueiro Da Silva Mouta v. Portugal ( No 33290/96, 21/12/1999).

82 Ver Complementary Internacional Standards: Report on the study by the five experts on the content and scope of substantive gaps in the existing international instruments to combat racism, racial discrimination, xenophobia and related intolerance, A/HRC/4/WG.3/6, 27 agosto de 2007, párrafo 20.

83 Ver: Beard v. the United Kingdom (№ 24882/94, 18/01/2001); Chapman v. the United Kingdom (№ 27238/95, 18/01/2001); Coster v. the United Kingdom ( $\left.N^{\circ} 24876 / 94,18 / 01 / 2001\right)$; Jane Smith v. the United Kingdom ( $\mathrm{N}^{\circ}$ 25154/92, 18/01/2001); y Lee $v$. the United Kingdom ( $\left.{ }^{\circ} 25289 / 94,18 / 01 / 2001\right)$. 
indirecta, en casos en que el trato igual tiene efectos desproporcionadamente adversos para los miembros de un grupo en particular" ${ }^{\prime 4}$. Al mismo tiempo, el examen sobre si una norma es razonable o no es una cuestión que está íntimamente ligada, y a menudo depende, de quién decida sobre el asunto. Como señala un autor, "[l]a discriminación sistemática suele ser el resultado de desigualdades fuertemente arraigadas en lo más profundo de la estructura social y se manifiestan como normas e interpretaciones comunes" ${ }^{\prime 85}$. Las opiniones sociales predominantes no siempre son la mejor prueba de lo que es razonable. En última instancia, quién toma la decisión puede ser tan importante, como la prueba para determinar qué constituye discriminación.

\footnotetext{
84 Wildhaber, supra, 71-72.

85 Choudhury supra, 41.
} 